\title{
Direitos humanos e minorias: o dogma da homossexualidade
}

\begin{tabular}{lcc}
\hline $\begin{array}{l}\text { Viviane Bastos Machado } \\
\text { Milton Junior Barros Araújo }\end{array}$ & $\begin{array}{l}\text { Professora de Direito na Faculdade Metropolitana São Carlos } \\
\text { (FAMESC). }\end{array}$ & E-mails: vivianembastos@hotmail.com \\
\hline miltonibarros@hotmail.com
\end{tabular}

Recebido em: 20 fev 2018. Aceito em: 30 ago 2018.

DOI: http://dx.doi.org/10.21674/2448-0479.45.632-642

\section{Resumo}

O presente artigo aponta questões decorrentes ao direito à liberdade de escolha, no âmbito sexual destancando-se por sua diferenciação ao modelo tradicional de família e de interesses sociais, abordando o tema da homossexualidade em contrapartida ao interesse pregado como convencional, caracterizando desta forma, parte da chamanda "minoria" em âmbito de relações sociais de direito. Assim, o trabalho sob análise busca o direito à liberdade e igualdade como garantia individual a todos sem distinção, inclusive quanto a sua orientação sexual, de forma a versar sobre o princípio da dignidade da pessoa humana, em relação a todas as questões que envolvem sua construção.

Palavras-chave: Dignidade. Homossexualidade. Liberdade. Minorias.

\section{Abstract}

\section{Human Rights and Minorities: The Dogma of Homosexuality}

The present article points out issues related to the right to freedom of choice in the sexual sphere, being distinguished by its differentiation from the traditional model of family and social interests, addressing the theme of homosexuality in counterpart to the interest preached as conventional, characterizing in this way, part of the chamanda "minority" in the scope of social relations of law. The work was developed through qualitative research with doctrines and scientific articles, in the search of the understanding of the necessary phenomenon of inclusion of all the minorities. Thus, the aforementioned analysis seeks the right to freedom and equality as an individual guarantee to all without distinction, including as to their sexual orientation, in order to address the principle of the dignity of the human person, in relation to all issues that involve its construction being the understanding reached through this research, demonstrating by its results that although the Brazilian normative system is advanced, it still lacks cultural and inspection tools so that respect for all worthily is effectively established in the national reality.

Keywords: Dignity. Homosexuality. Freedom. Minorities. 


\section{Introdução}

As minorias estão presentes em todas as sociedades, são formadas a partir de indivíduos com aspectos diferentes, características físicas ou comportamentais, que destoam do grupo majoritário social, seja por cor, sexo, origem, educação, condição econômica ou orientação sexual, contudo os direitos destes devem ser respeitados e levados em consideração no meio social. Um grupo classificado como minoria são os homossexuais que, divergem do sensu comum, elegendo como parceiros pessoas do mesmo sexo, diferenciando-se assim do que é considerado "normal" aos olhos da sociedade, acostumada com uma ordem específica e que apresenta grandes dificuldade na evolução de conceitos e estruturas sociais.

O ordenamento jurídico vem em busca da reorganização do direito à igualdade e liberdade, essenciais na construção de uma sociedade equilibrada em busca da construção de elementos formadores beneficiando a todos, independentemente, de suas escolhas personalíssimas. Neste interim, são beneficiados uma ampla gama de indivíduos, que não se "encaixam" no que é referenciado como comum, por cor, por sexo, por origem, por idade. Assim, os princípios, leis, normas vêm surgindo em uma escala cada vez maior para a promoção da igualdade de condições a todos, de modo que podemos exemplificar como avanço a Declaração Universal dos Direitos Humanos. As palavras, os atos e as formas de expressão intimidadores e repreensivos podem abalar psicologicamente qualquer pessoa, independentemente de quem seja, sendo importante abordar a questão da liberdade e no que se trata dos homossexuais a liberdade frente aos direitos sexuais. Haja vista que, estes muita das vezes são ignorados por não fazerem parte da sociedade heteronormativa pregada pela massa social.

Cabe salientar ainda a falta de oportunidade e preconceito junto nos diversos âmbitos, inclusive trabalhista, que muitas das vezes veem questionadas suas habilidades físicas ou intelectuais pelo simples fato de terem uma orientação sexual que destoa das demais, o que gera entre outros prejuízos, de evolução digna do ser humano em seu meio social.

\section{O fator social da homossexualidade perante a sociedade}

A sociedade é eclética, formada por grupos de indivíduos que contenham afinidades entre si, e daí se formam o que muitos chamam de "minorias", e destas minorias surgiram-se grandes nomes, grandes movimentos, e grandes gerações. Quando se fala em algo que todos sabem do que se trata, mas ignoram tal assunto, como no caso da homossexualidade, com medo de se posicionar, pois vivemos em uma sociedade heteronormativa e o que foge do padrão é visto como algo errôneo. Deste modo, na maioria das vezes as pessoas criadas com indivíduos que compartilham desta ideologia, são orientadas desde criança que sentir atração física ou emocional por uma pessoa do mesmo sexo é algo totalmente errado e intolerável, passamos então a enfrentar um problema cultural.

No que tange a heterossexualidade, é de suma importância destacar:

[...] é tida como parâmetro normal/natural da sexualidade, são raros os casos de ofensa ao direito de se sentir atraído ou de amar o sexo oposto. Quando o desejo para o sexo idêntico é camuflado na bissexualidade, também são incomuns as turbações

à intimidade, pela pressuposição heterossexual. Ao contrário, devido à ignorância 
científica e ao preconceito, a orientação afetiva homossexual ainda esbarra em reprovabilidades dos mais variados graus, sendo comuns atentados ou insinuações verbais, gestuais e, até mesmo, agressões físicas aos que não ocultam ou deixam refletir as suas homossexualidades. (DEUS, 2005, p.01).

Nos primórdios da humanidade a homossexualidade já foi admirada, com passar do tempo tornou-se condenável e hoje o tema virou um dogma que pouco se debate, muitas vezes com medo de se posicionar sobre o assunto, com receio de julgamentos perante a sociedade. Mas, é fato notório que essa geração tão promissora, onde cada vez mais vem conquistando seu espaço e que não pode ser mais ignorada ou mesmo ocultada, já se tornou um fator social. Passando pelo estágio de ser considerada uma doença mental, uma opção e hoje debatida como uma condição. Firmada tal tese graças aos movimentos de conscientização LGBTs, que afirmam não se escolher entre ser homo ou heterossexexual, isso já se encontra na sua essência, desenvolvida na maior parte durante a adolescência ou até mesmo desde crianças.

O autor Enéas Castilho Chiarini Júnior (2004), se enuncia sobre a existência da homossexualidade o certo é de que "desde que o mundo é mundo", a homossexualidade existe, e não será proibindo que se acabará com ela pois, é algo que se encontra no cerne da sociedade e não se pode evitar. Relativamente, aqueles que condenam a homossexualidade, alegando ser contra a natureza humana, em vários seguimentos, bem como nas raízes religiosas, deve-se destacar que o cerceamento da liberdade de manifestação, não varrerá a homossexualidade, assim deve-se encontrar o equilíbrio indispensável às relações sociais e jurídicas quanto às minorias e suas amplas possibilidades de manifestação.

Borges defende um ponto de vista muito debatido e defendido entre os movimentos LGTBs, sendo:

\begin{abstract}
Ninguém escolhe ser homossexual. $O$ desejo emocional e sexual por pessoas do mesmo sexo surge espontaneamente, da mesma forma que acontece com os heterossexuais. O que as pessoas podem escolher é se irão ou não ter comportamentos homossexuais. Uma coisa é a orientação homossexual (desejo, atração física e emocional), outra é o comportamento homossexual (relações amorosas e/ou sexuais com parceiros do mesmo sexo). (BORGES, 2008, p.01)
\end{abstract}

Assim, o que se procura defender é a ampla possibilidade de se conquistar a manifestação plena dos interesses individuais de cada ser humano.

\title{
Os direitos humanos essência do ser humano
}

O direito é uma ciência normativa, composta por regras e princípios que regem uma sociedade, passando deste modo pelo campo social, ou seja, pela reprodução dos fatores sociais, em relação ao direito promovido pela sociedade. Nesse sentido, os direitos humanos sofreram grandes evoluções no correr do tempo, firmando o seguinte entendimento: 
Considerando que o reconhecimento da dignidade inerente a todos os membros da família humana e de seus direitos iguais e inalienáveis é o fundamento da liberdade, da justiça e da paz no mundo, Considerando que o desprezo e o desrespeito pelos direitos humanos resultaram em atos bárbaros que ultrajaram a consciência da Humanidade e que o advento de um mundo em que os homens gozem de liberdade de palavra, de crença e da liberdade de viverem a salvo do temor e da necessidade foi proclamado como a mais alta aspiração do homem comum, Considerando essencial que os direitos humanos sejam protegidos pelo Estado de Direito, para que o homem não seja compelido, como último recurso, à rebelião contra tirania e a opressão, Considerando essencial promover o desenvolvimento de relações amistosas entre as nações, Considerando que os povos das Nações Unidas reafirmaram, na Carta, sua fé nos direitos humanos fundamentais, na dignidade e no valor da pessoa humana e na igualdade de direitos dos homens e das mulheres, e que decidiram promover o progresso social e melhores condições de vida em uma liberdade mais ampla, Considerando que os Estados-Membros se comprometeram a desenvolver, em cooperação com as Nações Unidas, o respeito universal aos direitos humanos e liberdades fundamentais e a observância desses direitos e liberdades, Considerando que uma compreensão comum desses direitos e liberdades é da mais alta importância para o pleno cumprimento desse compromisso, A Assembléia Geral proclama A presente Declaração Universal dos Diretos Humanos como o ideal comum a ser atingido por todos os povos e todas as nações, com o objetivo de que cada indivíduo e cada órgão da sociedade, tendo sempre em mente esta Declaração, se esforce, através do ensino e da educação, por promover o respeito a esses direitos e liberdades, e, pela adoção de medidas progressivas de caráter nacional e internacional, por assegurar o seu reconhecimento e a sua observância universais e efetivos, tanto entre os povos dos próprios Estados-Membros, quanto entre os povos dos territórios sob sua jurisdição. (DECLARAÇÃO UNIVERSAL DOS DIREITOS HUMANOS, 2009- Preâmbulo).

A partir do preâmbulo da Declaração Universal dos Direitos Humanos, pode-se obter uma vasta visão dos princípios base, que norteiam os direitos humanos, como a dignidade, liberdade, igualdade e justiça. Desta feita, salienta-se que qualquer cidadão é portador de direitos, e estes devem ser respeitados, nesse sentindo à luz da Constituição brasileira de 1988, tem-se como fundamento do Estado brasileiro, a cidadania e principalmente a dignidade da pessoa humana, nesse contexto expressa o doutrinador Sérgio Cavalieri Filho:

Entre os superiores princípios (valores) consagrados na Constituição de 1988, merece especial destaque o da dignidade da pessoa humana, colocado como um dos fundamentos da República Federativa do Brasil (art. 1ํㅡ. III). Temos hoje o que podemos chamar de direito subjetivo constitucional à dignidade. Ao assim fazer, a Constituição colocou o homem no vértice do ordenamento jurídico da Nação, fez dele a primeira e decisiva realidade, transformando os seus direitos no fio condutor de todos os ramos jurídicos. Isso é valor. (CAVALIERI FILHO, 2005, p. 61).

O dicionário Houaiss e Villar define dignidade como sendo "consciência do próprio valor; honra; modo de proceder que inspira respeito; distinção; amor próprio." (HOUAISS; VILLAR, 2004, p. 248), em apertada síntese, valendo-se das nobres palavras de Sarlet, define-se a dignidade da pessoa humana sendo:

[...] qualidade intrínseca e distintiva reconhecida em cada ser humano que o faz merecedor do mesmo respeito e consideração por parte do Estado e da comunidade, implicando, neste sentido, um complexo de direitos e deveres fundamentais que assegurem a pessoa tanto contra todo e qualquer ato de cunho degradante e desumano, como venham a lhe garantir as condições existenciais mínimas para uma vida saudável, além de propiciar e promover sua participação ativa e co - responsável nos destinos da própria existência e da vida em comunhão com os demais seres 
humanos, mediante o devido respeito aos demais seres que integram a rede da vida.(SARLET, 2011, p. 73).

A norma constitucional que tutela a dignidade da pessoa humana como fundamento da República se firma no sentido de garantir a busca do Estado brasileiro em proporcionar ao indivíduo condições para que se possa ter uma vida com dignidade em seu amplo sentido, sendo, portanto, um fim e não um meio pelo qual o Estado atinge suas finalidades. (TAVARES, 2010).

Dada tal análise, podemos perceber que a dignidade da pessoa humana é um supraprincipio, ou seja, serve de base a todo ordenamento jurídico, sendo que a constituição em seu título II, mais expressamente em seu artigo $5^{\circ}$ prevê uma série de direitos e garantias fundamentais, como direito a vida, a liberdade, igualdade. Contudo debruçando-se sobre o tema em questão a homossexualidade pode se esbarrar no direito a liberdade, passando pelos direitos da sexuais.

Como Lopes leciona (2009) a solução do problema não é simples e deve ser cobrada de toda a sociedade, e não apenas do Estado. Num primeiro momento, é importante que a sociedade abandone a omissão cômoda, dando ao tema importância necessária, colocando-o em evidência sob debates públicos, seminários, palestras e no meio acadêmico desde o início da formação da educação, pois só assim as pessoas poderão tomar contato com o assunto, refletir sobre ele, seja a nível individual, com uma mudança de comportamento, seja a nível coletivo, participando de ações e oferecendo sugestões nos meios de convivência social, que possam resultar na promoção da igualdade e destituir qualquer forma discriminatória do direito à liberdade.

$\mathrm{Na}$ busca de sua melhor compreensão, Rios debruça sobre tal tema esclarecendo que "... a ideia de direitos sexuais na perspectiva dos direitos humanos aponta para a possibilidade do livre exercício responsável da sexualidade..." (2006, p. 72 ). Portanto, está diretamente vinculado ao direito à liberdade, Rios inclusive menciona sendo "direito democrático da sexualidade".

O que é notório no decorrer do dia a dia da nossa sociedade heteronormativa, é que o indivíduo que se destoa do padrão criado pela sociedade, é de forma brutal apedrejado, seja por palavras, olhares, ou até mesmo agressão física. Fatos estes simplesmente ocorridos devido sua orientação sexual ser diversa daquela à qual o autor dos gestos em questão acha correta, ou seja, lesa-se não só a pessoa envolvida naquela situação, mas sim toda sociedade e o Estado, haja vista que a lesão ocorrida põe em degradação o direito da liberdade abarcado do seu livre direito a escolha de orientação sexual.

A preocupação da temática ora desenvolvida se torna ainda mais emergência, tendo em vista fatos noticiados de intolerância, especialmente decorrentes de grupos extremistas de limpeza étnica, social, sexual, o mundo viveu no alvorecer do século XX o início e o fim da Segunda Grande Guerra, marcada pela intolerância e abstenção total do direito à liberdade. Desta forma, a necessidade de discutir elementos de fortalecimento de direitos deve ser sempre presente na realidade jurídica, a desconstrução de paradigmas de discriminação deve ser a política de estado, bem como de segmentos formadores de opinião como associações, a família e a academia, que efetivam de maneira plena como se dará a realidade da ordem jurídica. 
Consoante de que os direitos sexuais são viabilizados pelo direito à liberdade, e que estes são direitos fundamentais protegidos por nosso ordenamento jurídico, deste modo, a Constituição brasileira de 1988, prevê em seus artigos $5^{\circ}$, parágrafos $1^{\circ}$ e $2^{\circ}$ :

$\S 1^{\circ}$ As normas definidoras dos direitos e garantias fundamentais têm aplicação imediata.

$\S 2^{\circ}$ Os direitos e garantias expressos nesta Constituição não excluem outros decorrentes do regime e dos princípios por ela adotados, ou dos tratados internacionais em que a República Federativa do Brasil seja parte.

Deste modo, a nossa Carta Magna é bem clara no sentido de que os direitos fundamentais elencados em seu texto, sejam ele explícitos ou implícitos são de aplicação imediata, valendo-se de uma interpretação a contrário sensu, eles independem de regulamentação de legislação infraconstitucional para terem aplicação em casos concretos. Os argumentos decorrentes dos direitos fundamentais são balizados pela construção normativa universal dos direitos humanos, pressupondo que a essência dos derivados são a reafirmação do indivíduo como fim em si mesmos, e não como meio na construção de uma realidade jurídica.

\title{
Os novos direitos na composição Familiar
}

Com a evolução do direito contemporâneo foi se reconhecendo cada vez mais a legalidade de casais homoafetivos bem como a paternidade. Nesse sentido Grossi descreve:

\begin{abstract}
Há muitas formas de um homem homossexual viver a paternidade (...) o primeiro tipo, mais comum, é o de pais homossexuais que tiveram filhos numa relação heterossexual. O segundo tipo de filiação é por adoção, o que em geral é um processo muito complicado para homens sozinhos. Uma terceira forma, mais rara, é o uso do ventre de aluguel, quando um homem paga uma mulher para ter a criança para ele (ou para um casal de gays). Finalmente, uma última possibilidade que me parece a mais rica como modelo teórico, é o caso de parentalidade envolvendo no mínimo três adultos. Em alguns casos, trata-se de dois casais (dois homens e duas mulheres) que resolvem ter filhos juntos, e resulta em uma família que tem duas mães e dois pais. As crianças são criadas entre duas casas, onde em uma tem dois pais e outras duas mães. Um outro tipo de arranjo é um casal, e aí pode ser ou um casal de duas mulheres, ou um casal de dois homens, com mais um indivíduo do outro sexo. O casal escolhe aquele que vai reproduzir com uma das mulheres que vão ter um filho; essa criança vai ter três adultos que a vão criar. (GROSSI, 1995, p.22).
\end{abstract}

Debruçando-se sobre tal assunto Sylvia Maria Mendonça do Amaral, esclarece sobre a posição do Supremo Tribunal de Justiça:

O Superior Tribunal de Justiça - STJ definiu em recente julgamento que as questões relacionadas ao reconhecimento de uniões homoafetivas deverão ser analisadas sob a ótica do Direito de Família. O ministro Luis Felipe Salomão, responsável pelo voto de desempate, determinou que a justiça do Rio de Janeiro analise o pedido de um casal homossexual que pretendia ver reconhecida a união estável de 20 anos. A decisão tem um importante efeito na medida em que faz com que as relações havidas entre pessoas do mesmo sexo sejam vistas como relações familiares já que deverão ser analisadas por juízes de varas de família. Os relacionamentos homoafetivos serão vistos como relações de amor, afeto enquanto se analisadas em varas cíveis, terminariam por ser tidas como sociedades de fato havidas entre os parceiros, onde se trata apenas das questões financeiras e patrimoniais. Esse é o principal efeito da decisão do STJ: a percepção de que as uniões de pessoas do mesmo sexo podem 
originar entidades familiares e não sociedades. (AMARAL, 2008, documento eletrônico)

Desta feita, é nítido que com a evolução social e costumeira, a própria jurisprudência brasileira vem se baseando no sentido teleológico das normas, fugindo do sentido literal da norma, haja vista que nossa legislação é retrógrada perante os fatos sociais do cotidiano, deste modo o julgador assume um papel muito mais relevante ao definir o mérito em questões como a tratada no presente artigo. Como bem ressalta a ex-desembargadora Maria Berenice Dias (2009, p. 103) dizendo:

\begin{abstract}
A orientação que alguém imprime na esfera de sua vida privada não admite quaisquer restrições. Há de se reconhecer a dignidade existente na união homoafetiva. $\mathrm{O}$ valor da pessoa humana assegura o poder de cada uma exercer livremente sua personalidade, segundo seus desejos de foro íntimo. A sexualidade está dentro do campo da subjetividade. Representa fundamental perspectiva do livre desenvolvimento da personalidade, e partilhar a cotidianidade da vida em parcerias estáveis e duradouras parece ser um aspecto primordial da existência humana.
\end{abstract}

O autor Marcos Rolim (2006) afirma que se tem, no Brasil, cerca de 200 mil crianças institucionalizadas em abrigos e orfanatos. A esmagadora maioria delas permanecerá nesses espaços de sofrimento e desamor até completarem seus18 anos, pois estão fora do padrão aceitável para adoção. Tudo o que essas crianças esperam e sonham é o direito de fazerem de uma família no interior das quais sejam amadas e respeitadas através de um carinho que nunca obtiveram. No entanto graças ao preconceito e a tudo aquilo que ele oferece de violência e intolerância, tais crianças dificilmente passaram por um processo de adoção, com objetivo de construção não somente da família como objeto primário deste contexto, mas pormenorizando a estrutura de uma digna vida a tais crianças, como o máximo princípio do melhor para sua realidade social e afetiva.

Contudo, o contexto de tal realidade vem se modificando junto aos tribunais, abrindo a possibilidade, cada vez mais presente, de adoção por casais de diferentes orientações, especialmente homossexuais. A decisão do Supremo Tribunal Federal (ADI 4277 e ADPF 132) que viabilizou através da mutação constitucional inspirada no "princípio da interpretação conforme à Constituição", declarando direitos paritários sobre a união estável nas relações familiares homoafetivas, viabilizando a reconstrução do sistema de direito de família, mas muito há que avançar, a estrutura deste direito se moderniza constantemente adequando-se ao contexto social, mas o avanço paradigmático social precisa ser acompanhado pela construção normativa - o que não ocorre - no entanto o fato impulsiona o jurista no caminho de sua modernização.

\title{
A Homossexualidade como um Dogma no Mercado de Trabalho
}

No mercado de trabalho, os homossexuais muita das vezes, são ignorados, pela falta de oportunidade ou mesmo por medo de humilhações e aborrecimentos, uma área pouco explorada neste dilema e especialmente esquecida de qualquer atividade regulamentadora, sendo certo que a homossexualidade culturalmente sempre foi tratada como um tabu perante a sociedade, chegando a 
ser considera uma doença mental, no entanto é nítido que a homossexualidade já fora retirada a bastante tempo do rol de doenças:

[...] foi retirada da lista de "doenças" do Classificador Internacional de Doenças - CID, em louvável iniciativa do Conselho Federal de Medicina, no ano de 1985, tornando sem efeito o código 302 do CID, o qual considerava a homossexualidade como desvio ou transtorno sexual, antecipando-se, assim, à própria Organização Mundial de Saúde. (FIGUEIREDO, 2006, p. 84).

Apesar do entendimento ainda chocar na atualidade, os profissionais homossexuais enfrentam constantes desafios na aceitação em seu âmbito de trabalho, no entanto não é comum este dilema, haja visto que tais enfrentamentos se iniciam muitas vezes em seu ceio familiar, relativamente por questões culturais de uma sociedade formada por dogmas heterormativos. Para Fernandes (2007, p.10), "o preconceito contra os homossexuais começa pela própria família, passando pelos amigos e colegas de trabalho até esbarrar em determinados segmentos da sociedade".

Muitos dos profissionais que definem a sua orientação sexual por indivíduos do mesmo sexo, sofrem assédio moral, abalando sua confiança e consequentemente deteriorando sua autoestima. Nesse sentido Pedrosa leciona:

O estresse emocional crônico gerado pela humilhação comprometerá a saúde física e a estrutura de personalidade do vitimado desencadeando baixo autocontrole emocional, baixa autoestima e atitudes autodestrutivas que podem evoluir para a incapacidade produtiva, desemprego, morte, enfarte, problemas psiquiátricos, derrame cerebral, isolamento social, suicídio, uso de drogas, marginalidade, incapacidade de estabelecer ligações afetivas, incompetência nas relações interpessoais, timidez, dificuldade de se comunicar, vingança podendo planejar o assassinato do algoz, promoção de atos de sabotagem na empresa e o aparecimento de uma disfunção sexual associada. Constitui o chamado risco invisível, nas relações cotidianas de trabalho. (PEDROSA, 2009, p.1)

Sempre haverá uma violação grave ao direito a igualdade consagrado pela nossa carta política, se for levada em consideração a orientação sexual de um indivíduo para a contração deste como empregado, tendo como vítima não somente o cidadão em questão, mas o próprio Estado que perde em seu cerne o conceito da liberdade e igualdade como valores de essência plena. Valendo-se do nobre pensamento do doutrinador Deus (2005), deve-se pregar que as pessoas que se sintam lesadas, no direito fundamental de livre e responsável expressão da orientação sexual que é uma escolha sua, não podem se omitir de denunciar as perturbações que Ihes firam a afetividade e a sua própria dignidade. Mesmo que imperfeita, a via judicial é a mais viável para ajustar conflitos oriundos de atentados à sexualidade. O pedido de indenização por danos morais é uma alternativa para sancionar o desrespeito a este espectro essencial da intimidade e punir os autores de tal atrocidade.

Sergio Barradas Carneiro, se manifesta acerca da decisão do STF, em reconhecer a união estável homafetiva dizendo:

A recente decisão do Supremo Tribunal Federal (STF) de reconhecer a união estável entre pessoas do mesmo sexo no Brasil continua tendo repercussões em toda a 
sociedade brasileira e fomentando amplo debate no Congresso Nacional. Em minha avaliação, o Supremo consolidou o que o Legislativo ainda não havia conseguido: reconhecer uma prática social já existente em nosso País. Outras nações já caminharam nesse sentido, há mais tempo. Por exemplo, em 1993, o Conselho Econômico e Social da Organização das Nações Unidas (ONU) aceitou a Associação Internacional de Gays e Lésbicas (Ilga) como um dos seus membros. Esta foi uma das maiores conquistas do movimento homossexual, no final do século passado, para se estabelecer em quase todas as sociedades do mundo. A razoabilidade deve prevalecer, também, para afastar a hipocrisia. Somos uma sociedade hipócrita. Aplaudimos cantores e artistas, símbolos de comportamento homossexual, mas hostilizamos nossos vizinhos, pelo mesmo motivo. Transformamos transexuais em símbolo sexual feminino, mas não lhes damos o direito a documentos de mulher. Reprovamos o casal lésbico da novela, mas assistimos e toleramos cenas de violência, o assassinato de crianças e mendigos, a corrupção e o desrespeito com as pessoas mais simples do povo, sob os mais diversos aspectos. Somos uma sociedade hipócrita, que, aos poucos, vai-se dando conta da falta de razoabilidade e injustiça do seu comportamento. (CARNEIRO, 2011, documento eletrônico)

E todo o desabafo manifestado no posicionamento do doutrinador decorre do desrespeito aos elementos essenciais de um Estado que se declara como "Democrático de Direito", não podendo assim, ser construída a democracia sem respeito à justiça social através da liberdade e da igualdade como máximas de uma formação, para atingir o elemento da dignidade humana.

Finalmente, ressalta-se que os direitos são capazes de transpassar séculos e barreiras, são alimentos de formação de novas realidades sociais, nos adaptamos a ele e eles se adaptam os interesses sociais, assim, debater um caminho de maior plenitude não é somente um interesse, mas um dever como cidadão participativo que vivencia todos os dias a hipocrisia social.

\section{Considerações finais}

Mesmo que a opinião atual seja mais favorável à questão da homossexualidade do que a tempos passados, com leis especiais contra a homofobia e processos de conscientização, ainda são comuns manifestações de preconceito para com indivíduos vistos como diferentes, sendo corriqueiro ao longo de todo a história da humanidade o hábito de rejeitar o diferente, o incomum, muitas vezes por apego a tradição e ao costume.

Assim, como outros grupos denominados como "minorias", os homossexuais passam por dificuldades de aceitação, mas é algo que vai além da simples falta de anuência das demais pessoas, atingindo uma escala pessoal, interna, ao passo que o dito "sair do armário" pode ou não consistir em vergonha para seus familiares e amigos e o medo de tomar a decisão pode acarretar alterações psicológicas profundas.

Por mais difícil que seja, aos apegados ao modelo comum de relacionamento afetivo, ainda é necessário ter consideração pelas escolhas dos que preferem a divergência, tendo em vista que o fundamental é o respeito, pois mesmo uma pessoa não concordando com a opinião do outro, ainda precisa respeitá-la, visto que todos são livres para optar.

Como destacado no texto, não há que se falar em doença ou escolha, ou ainda em um tipo de enfermidade curável, sobre a homossexualidade, o que precisa de cura neste contexto são os elementos de concretização de direitos e de liberdade de manifestação. 
Ressalta-se ainda que os parâmetros sexuais impostos pela sociedade de forma brutal, não podem existir em um Estado democrático de direito, como consagrado no texto constitucional, é de fundamental relevância que cada indivíduo, tenha uma vida digna e livre da melhor forma que the convenha, sem afetar ao próximo com suas opiniões ou escolhas.

Assim, considera-se como essência de uma sociedade saudável respeito mútuo e a tolerância como valores sociais e culturais produzidos por escolha, mas também com construção cotidiana, não falar, não debater, não construir leva toda sociedade a uma cegueira constrangedora, pois o desrespeito é o alimento da não efetividade de direitos.

\section{Referências}

AMARAL, S. M. M. do. União homossexual como direito de família. Migalhas. 2008. Disponível em: $<$ https://www.migalhas.com.br/dePeso/16,Ml70205,41046-

Uniao+homossexual+como+Direito+de+Familia> Acesso em: 27 fev. 2017.

BORGES, K. Mitos e verdades sobre a homossexualidade. Disponível em:

$<$ http://www.clicfilhos.com.br/site/display_materia.jsp?titulo=Mitos+e+verdades+sobre+a+homossexua lidade>. Acesso em: 04 de mar. de 2017.

BRASIL. Constituição da República Federativa do Brasil, de 05 de outubro de 1988. 20. ed. Brasília: Câmara dos Deputados, Coordenação de Publicações, 2017.

CARNEIRO, S. B. Os homossexuais e o direito. 2011. Disponível em:< http://congressoemfoco.uol.com.br/opiniao/colunistas/os-homossexuais-e-o-direito//>. Acesso em: 06 de fev. 2017.

CAVALIERI FILHO, S. Programa de Sociologia Jurídica. 11. ed. Rio de Janeiro: Forense, 2005.

CHIARINI JÚNIOR, E. C. A união homoafetiva sob o enfoque dos direitos humanos. Jus Navigandi, Teresina, ano 8, n. 235, 28 fev. 2004. Disponível em:

<http://jus2.uol.com.br/doutrina/texto.asp?id=4902>. Acesso em: 27 fev. 2017.

DECLARAÇÃo Universal dos Direitos Humanos. Disponível em:

http://www.mj.gov.br/sedh/ct/legis_intern/ddh_bib_inter_universal.htm. Acesso em mar. 2017.

DEUS, E. de. Família: Para além do "Numerus Clausus". Disponível em:

<http://www.ibdfam.com.br/public/artigos.aspx?codigo=262>. Acesso em: 25 de fev. 2017.

DIAS, M. B. União homoafetiva: o preconceito e a justiça. 4. ed. São Paulo: Revista dos Tribunais, 2009.

FERNANDES, J. G. União Homoafetiva como Entidade Familiar. Disponível em: $<$ http://www.nagib.net/variedades_artigos_texto.asp?tipo=14\&area $=3 \& i d=448>$. Acesso em: 03 de mar. de 2017.

FIGUERÊDO, L. C. de B. Adoção para homossexuais. Curitiba: Juruá, 2006.

GHIRALDELLI JUNIOR, P. Os gays e seus pais. Artigo de blog de 25.07.2009. Disponível em: < https://ghiraldelli.wordpress.com/2009/07/25/os-gays-e-seus-pais/ >. Acesso em: 25 fev. 2017.

GROSSI, M. P. Masculinidades: Uma Revisão Teórica. Antropologia em primeira mão. Programa de Pós-Graduação em Antropologia Social. Florianópolis: Universidade Federal de Santa Catarina, 1995. 
HOUAISS, A.; VILLAR, M. de S. Minidicionário Houaiss de língua portuguesa. 2. ed. rev. e aum. Rio de Janeiro: Objetiva, 2004.

LOPES, O. B. A Questão da Discriminação no Trabalho. Disponível em:

<http://www.planalto.gov.br/ccivil_03/revista/Rev_17/Artigos/art_otavio.htm>. Acesso em: 25 fev. 2017.

PEDROSA, J. B. O assédio moral e a auto-estima do homossexual. Disponível em:

$<$ http://www.armariox.com.br/conteudos/colunistas/pedrosa/autoestima.php>. Acesso em: 10 mar. 2017.

RIOS, R. R. Para um direito democrático da sexualidade. Horiz. Antropol., Porto Alegre, v. 12, n. 26, 2006.

ROLIM, M. Casais homossexuais e adoção. Disponível

em: <http://www.rolim.com.br/cronic162.htm.> Acesso em: 30 set. 06.

SARLET, I. W. Dignidade da pessoa humana e direitos fundamentais na Constituição Federal de 1988. 9. ed. rev. atual. Porto Alegre: Livraria do Advogado, 2011.

TAVARES, A. R. Curso de direito constitucional. 8.ed. rev. e atual. São Paulo: Saraiva, 2010. 